\title{
Tetracycline and benign intracranial hypertension: report of five cases
}

\author{
BARRY N J WALTERS, SASSON S GUBBAY
}

\begin{abstract}
Benign intracranial hypertension occurred in four young women taking tetracycline for acne; two were also taking vitamin $A$. In a fifth case a 14-year-old boy developed papilloedema after taking a short course of tetracycline for bronchitis. All symptoms disappeared soon after stopping the drugs, though in two cases the papilloedema persisted for many months.

Benign intracranial hypertension should be sought in any young woman complaining of headache during treatment with tetracycline. Moreover, young women given vitamin $A$ and tetracycline in combination for acne may be at special risk and should be kept under surveillance.
\end{abstract}

\section{Introduction}

Tetracycline is a well-recognised cause of raised intracranial pressure in infancy, ${ }^{12}$ but few cases have been documented in adults. ${ }^{3}$ Only two such cases have been reported from Australia, and both were in adolescent girls with acne. ${ }^{45}$ Another cause of the syndrome is acute or long-term overdosage of vitamin A. ${ }^{6}$ ?

We describe five young adults with benign intracranial hypertension associated with tetracycline. Four of them were women who had been taking the drug for acne, two of whom had also been taking vitamin $\mathbf{A}$.

\section{Case 1}

A 19-year-old trainee nurse was admitted to this hospital in May 1972 after eight days of throbbing frontal headache, unsteadiness, nausea, and tinnitus. Physical examination showed only papilloedema. Fifteen months before she had been prescribed tetracycline and vitamin $\mathbf{A}$ for acne. She had continued to take the tetracycline until admission but had stopped the vitamin A after nine months. Results of routine blood biochemical tests and cell count were normal, as were an electroencephalogram, radioisotope brain scan, right carotid and vertebral angiograms, and pneumoencephalogram. With the patient laterally recumbent the lumbar cerebrospinal fluid pressure was $160 \mathrm{~mm}$ water; protein and sugar concentrations were $0.16 \mathrm{~g} / 1$ and $5.3 \mu \mathrm{mol} / 1(0.1 \mathrm{mg} / 100 \mathrm{ml})$ respectively, and microscopy showed $5 \times 10^{6}$ lymphocytes $/ 1\left(5 / \mathrm{mm}^{3}\right)$.

Dexamethasone, administered in decreasing dosage for four weeks, exacerbated the acne, and four days after discharge tetracycline was reinstituted. Papilloedema rẹgressed and headache did not recur. The fundi were normal seven weeks after admission and had remained so when she was last seen 21 months later, still taking tetracycline.

\section{Case 2}

A 22-year-old typist presented in June 1974 with a history of throbbing frontal headache present intermittently for 14 weeks, sometimes accompanied by blurring in the right eye. One week before onset tetracycline $250 \mathrm{mg}$ daily had been prescribed for moderately severe acne. She had stopped taking an oral contraceptive nine months

Department of Neurology, Royal Perth Hospital, Western Australia BARRY N J WALTERS, MB, BS, neurological registrar SASSON S GUBBAY, MD, FRACP, head of department before. Examination showed an obese woman with right-sided papilloedema and slight concentric constriction of both visual fields. Routine blood tests and investigations including radioisotope brain scan, bilateral carotid angiography, and pneumoencephalography showed nothing abnormal. An electroencephalogram was mildly abnormal without focal or diagnostic features. Spinal tap with the patient lying on her side disclosed a lumbar cerebrospinal fluid pressure of $140 \mathrm{~mm}$ water, protein concentration $0.23 \mathrm{~g} / \mathrm{l}$, and norma microscopical appearances.

Despite stopping tetracycline on admission, instituting a course of dexamethasone and acetazolamide, and tapping the cerebrospinal fluid on three further occasions over six months, the papilloedema had remained unchanged in August 1975. Her symptoms had disappeared on the fifth day after admission.

\section{Case 3}

This 18-year-old woman had had recurrent otitis media in childhood, and a tympanoplasty had been performed in 1975. There was no further ear trouble. In January 1977 she began taking tetracycline $1 \mathrm{~g}$ daily for acne. In February vitamin $\mathrm{A}$ was added in a dose of 50000 units on alternate days. About three weeks later she developed morning bitemporal headache, vomiting, and diplopia. Examination disclosed bilateral papilloedema, partial abducens palsies, and a minor conductive hearing loss on the left. An electroencephalogram contained a mild excess of non-focal and non-specific theta activity. Computed tomograms (CT scans) of brain and posterior fossa showed some enlargement of the interpeduncular cisterns but were otherwise normal. Cerebrospinal fluid pressure was $300 \mathrm{~mm}$ water; the protein concentration was $0.15 \mathrm{~g} / \mathrm{l}$, and there were no cells.

Tetracycline and vitaimin A were discontinued, and after two weeks of dexamethasone she was without symptoms or signs. The headache had subsided after the lumbar puncture on day 2 of her hospital stay.

\section{Case 4}

An 18-year-old woman was admitted in April 1978 with headache of a few weeks' duration, vomiting, and diplopia. Her medical history included acne and psoriasis, and for six months she had been taking the semisynthetic tetracycline minocycline $100 \mathrm{mg}$ twice daily. Examination showed mild facial acne, bilateral papilloedema, and partial sixth-nerve palsies. A CT head scan was normal. At lumbar puncture the cerebrospinal fluid pressure was $140 \mathrm{~mm}$ water; protein concentration was $0.22 \mathrm{~g} / \mathrm{l}$; and glucose concentration and microscopical findings were normal.

Dexamethasone was given for three weeks, and the symptoms abated within a few days of admission. Minocycline was not reinstituted. Three weeks later she was well, without neurological abnormalities.

\section{Case 5}

A 14-year-old boy was first seen in September 1975 complaining of diplopia and photophobia for 24 hours. Four days before he had developed a cough with purulent sputum and been prescribed tetracycline $250 \mathrm{mg}$ four times daily. General examination showed no abnormality. There was mild bilateral papilloedema and partial right sixth-nerve palsy. Radioisotope brain scan and four-vessel cerebral angiography showed no lesions. At lumbar puncture cerebrospinal fluid pressure was $290 \mathrm{~mm}$ water; protein concentration was $0.11 \mathrm{~g} / \mathrm{l}$, and glucose concentration and microscopical findings were normal. Tetracycline was stopped and a short course of dexamethasone instituted. His symptoms disappeared within four days, and he was without symptoms or signs one month later.

In May 1977 he presented again with four weeks of throbbing posterior cervical pain increased by coughing. He was taking no drugs. 
Again there was papilloedema bilaterally. CT scan of the brain showed nothing abnormal. Cerebrospinal fluid pressure was $390 \mathrm{~mm}$ water. Lumbar puncture was performed monthly until May 1978, and thereafter he was well.

\section{Discussion}

That four of these five patients were women agrees with the acknowledged predominance of women in adult cases of benign intracranial hypertension. ${ }^{8}$ All the women had acne. Two were taking tetracycline alone and two a combination of tetracycline and vitamin $A$. In all cases the drugs were prescribed in low dosage.

The delay from beginning the drug to the onset of symptoms ranged from a few days to 15 months. Despite reinstituting tetracycline in case 1 intracranial hypertension did not recur. In case 5 symptoms and signs reappeared 19 months after the initial illness despite abstinence from all drugs. In case 2 papilloedema remained for 14 months after withdrawal of tetracycline, despite disappearance of all symptoms of raised pressure.

The chronological relation between the development of intracranial hypertension and exposure to tetracycline may vary appreciably, and recurrence of symptoms many months after apparent recovery occurs in up to one-tenth of patients. ${ }^{\circ}$ The prognosis, however, is good. ${ }^{8}$

Overdosage of vitamin A reportedly causes intracranial hypertension, ${ }^{7}$ but we could find no documented case after low dosage. Hence patients given tetracycline and vitamin $A$ in combination may be at greater risk of raised intracranial pressure than patients given either drug alone.

In two of the patients the cerebrospinal fluid pressure measured at lumbar puncture was under $150 \mathrm{~mm}$ water. This would not exclude the diagnosis, however, as the intracranial pressure measured by an intraventricular catheter ${ }^{10}$ may fluctuate widely in the disorder.

Although a drug may be implicated as the cause on rare occasions (indomethacin ${ }^{11}$ nalidixic $\operatorname{acid}^{12}$ nitrofurantoin ${ }^{13}$ ), in most cases the aetiology of the syndrome is not understood. Nevertheless, probably hormonal factors are present in cases associated with pregnancy, menarche, menstrual disturbances, oral contraceptives, obesity, hypoparathyroidism, and steroid treatment and withdrawal.
Computed tomography of the brain has greatly simplified the investigation and diagnosis of these patients. Probably none of our patients who were subjected to cerebral angiography or pneumoencephalography would today have been so managed.

The pathogenesis of this disorder remains a subject for speculation. Nevertheless, in each of our patients the cerebrospinal fluid protein concentration was at or below the lower limit of normal. This may reflect some disturbance in the secretory or filtratory function of the choroid plexus, leading to either an accumulation of cerebrospinal fluid or intracellular overhydration within the brain.

We are grateful to Dr M Sadka and Dr E Stewart-Wynne for permission to report their cases.

Requests for reprints should be addressed to: Dr S S Gubbay, Department of Neurology, Royal Perth Hospital, Box X2213, GPO, Perth WA 6001.

\section{References}

${ }^{1}$ Fields JP. Bulging fontanelle: a complication of tetracycline therapy in infants. F Pediatr 1961 ;58:74-6.

2 O'Doherty NJ. Acute benign intracranial hypertension in an infant receiving tetracycline. Dev Med Child Neurol 1965;7:677-80.

${ }^{3}$ Koch-Weser J, Gilmore EB. Benign intracranial hypertension in an adult after tetracycline therapy. $\mathcal{F} A M A 1967 ; 200: 169-71$.

4 Ohlrich GD, Ohlrich JG. Papilloedema in an adolescent due to tetracycline. Med f Aust 1977 ; i :334-5.

5 Beran RG. Pseudotumor cerebri associated with minocycline therapy for acne. Med F Aust 1980; :323-4

- Pasquariello PS, Schut L, Barnes P. Benign increased intracranial hypertension due to chronic vitamin A overdosage in a 26 month old child. Clin Pediatr (Phila) 1977;16:379-82.

${ }^{7}$ Feldman MH, Schlezinger NS. Benign intracranial hypertension associated with hypervitaminosis A. Arch Neurol 1970;22:1-7.

8 Weisberg LA, Benign intracranial hypertension. Medicine (Baltimore) 1975;54:197-207.

- Johnston I, Paterson A. Benign intracranial hypertension: diagnosis and prognosis. Brain 1974; $; 97: 289-300$.

10 Johnston I, Paterson A. Benign intracranial hypertension: CSF pressure and circulation. Brain 1974;97:301-12.

11 Konomi H, Tada $\mathrm{H}$. Indomethacin causing pseudotumor cerebri in Bartter's syndrome. N Englf Med 1978;298:855.

12 Boreus LD, Sundstrom B. Intracranial hypertension in a child during treatment with Nalidixic acid. Bri Med f 1967 ;ii :744-5.

${ }^{13}$ Mushet GR. Pseudotumor and nitrofurantoin therapy. Arch Neurol 1977; $34: 257$.

(Accepted 23 October 1980)

\section{SHORT REPORTS}

\section{Antipyrine clearance in psoriasis}

Our finding ${ }^{1}$ that the activity of aryl hydrocarbon hydroxylase, a microsomal mono-oxygenase, is decreased in the lesion-free epidermis, jejunum, and liver ${ }^{2}$ of patients with psoriasis suggests a widespread impairment of microsomal mono-oxygenase activity in this disease. We therefore compared the clearance of antipyrine, a drug eliminated primarily by hepatic microsomal oxidation, in normal subjects and patients with psoriasis.

\section{Subjects, methods, and results}

Thirty-five patients (16 men) with chronic discoid psoriasis (mean age 40.5 + SD 13.8 years) were matched for sex, age, and smoking habits with healthy volunteers. None had clinical or biochemical evidence of liver, renal, or thyroid disease. None had used systemic or topical drugs in the previous three weeks.

Salivary clearance of antipyrine was measured after a dose of $600 \mathrm{mg}$ (in gelatin capsules, bioavailability $=0.96)$. Saliva $(5 \mathrm{ml})$ was obtained at 3,5 , $8,15,24$, and 32 hours and antipyrine concentrations measured by gasliquid chromatography. Salivary clearance is the product of the eliminationrate constant (calculated by least squares regression analysis) and distribution volume (calculated by extrapolation).
Salivary clearance of antipyrine in the 17 patients who did not smoke $(41.9+$ SEM $3.1 \mathrm{ml} / \mathrm{min})$ was significantly $(t=2.49, \mathrm{p}<0.025)$ less than that in the 17 non-smoking controls $(51.9 \pm 2.9 \mathrm{ml} / \mathrm{min})$. By contrast, salivary clearance was similar in the 18 patients who smoked $(73.8 \pm 4.9 \mathrm{ml} / \mathrm{min})$ and their controls $(75.9+5.0 \mathrm{ml} / \mathrm{min})$. Hence antipyrine clearance was only slightly lower $(58.3+4.0 \mathrm{ml} / \mathrm{min})$ in all 35 patients compared with all 35 controls $(64 \cdot 2 \pm 3 \cdot 5 \mathrm{ml} / \mathrm{min})$. In patients and controls antipyrine clearance was significantly greater in smokers than non-smokers and was linearly related to daily cigarette consumption (patients $\mathrm{r}=0.67, \mathrm{p}<0.01$; controls $r=0.64, p<0.01$-figure).

\section{Comment}

The results show that in non-smokers salivary antipyrine clearance was lower in the patients with psoriasis than the controls. As the patients and controls were closely matched, had no evidence of disease, and were not taking drugs, we conclude that the difference was due to the psoriasis itself.

Salivary antipyrine clearance corresponds with plasma clearance ${ }^{3}$ and is determined by the activity of hepatic mono-oxygenase(s). Our observations therefore suggest that the reduced epidermal activity of aryl hydrocarbon hydroxylase in clinically normal, lesionfree skin of patients with psoriasis ${ }^{1}$ is part of a more widespread change in mono-oxygenase activity. This is further supported by our 